\title{
NEWBORN WITH INTRAUTERINE GROWTH RESTRICTION: ASSESSMENT OF PLASMATIC ERYTHROPOIETIN AND EARLY OUTCOMES
}

\author{
G.C. Zaharie ${ }^{1}$, M. Matyas ${ }^{1}$, L. Blaga ${ }^{1}$, M. Popa ${ }^{1}$, S. Bolboaca ${ }^{2}$, N. Schmidt ${ }^{1}$, T. Zaharie $^{3}$ \\ ${ }^{I}$ Neonatology, ${ }^{2}$ Medical Informatics and Biostatistics, University of Medicine and Pharmacy Iuliu Hatieganu \\ Cluj, ${ }^{3}$ Pathology, County Emergency Hospital Cluj, Cluj-Napoca, Romania
}

Introduction: The plasmatic level of EPO (erythropoietin) is high in the umbilical cord when oxygen supply is affected.

Aim: This study aimed to present the level of plasmatic EPO at birth as well as early complications occurred in newborns with Intrauterine Growth Restriction (IUGR).

Material and methods: A prospective study was done on 33 newborns in Neonatology Department ,Cluj, Romania between January 2008 - 2009(case group) and 32 healthy newborns(control group). The plasmatic level of EPO was determined with Elisa technique.

The following parameters were assessing for both groups: Apgar score, Astrup parameters, post asphyxia syndrome and the perinatal pathology. Epi Info 6 was used for statistical analysis.

Results: The study group had the weight of $1747.57 \pm 728.31 \mathrm{~g}$, ponderal index of $1.91 \pm 0.37$ and gestational age of $33.45 \pm 4.29$ weeks.

The EPO values were significant higher $56.49 \pm 7.80 \mathrm{mUI} / \mathrm{ml}$ in the study group versus control group $42.45 \pm 17.53 \mathrm{mUI} / \mathrm{ml}(\mathrm{p}=0.0001)$.The EPO was significantly higher also for those who developed meconium aspiration syndrome $(76.72 \pm 1199 \mathrm{mUL} / \mathrm{ml})$ compared to those who developed NTT (neonatal transient tachypnea)-23.60 $\pm 0.28 \mathrm{mUI} / \mathrm{ml} \quad(\mathrm{p}=0.004)$; and it was higher in those who needed inotrop support$111.05 \pm 49.14 \mathrm{mUI} / \mathrm{ml}$ compare with hemodynamic stable newborns $-46.52 \pm 52.11 \mathrm{mUI} / \mathrm{ml}(\mathrm{p}=0.017)$.

There could not be identified any significant differences between the EPO values of those who developed other complications (hypoxic-ischemic encephalopathy, infection or cerebral hemorrhage) $(p=0.398)$.

Conclusions: The plasmatic level of the EPO was significantly high in newborn who developed a severe respiratory pathology and were hemodynamic unstable.

There could not be identify any link between plasmatic level of EPO and HIE, sepsis, or cerebral hemorrhage. 